Vietnam Journal of Mechanics, VAST, Vol.42, No. 2 (2020), pp. 105-121

DOI: https://doi.org/10.15625/0866-7136/14663

\title{
EXPERIMENTS AND OPTIMIZATION FOR THE WEDM PROCESS: A TRADE-OFF ANALYSIS BETWEEN SURFACE QUALITY AND PRODUCTION RATE
}

\author{
Trung Thanh Nguyen ${ }^{1}$, Xuan Phuong Dang ${ }^{2}$, Truong An Nguyen ${ }^{1}$, \\ Quang Hung Trinh ${ }^{1, *}$ \\ ${ }^{1}$ Le Quy Don Technical University, Hanoi, Vietnam \\ ${ }^{2}$ Nha Trang University, Vietnam \\ E-mail: quanghung1020@gmail.com
}

Received: 04 December 2019 / Published online: 07 April 2020

\begin{abstract}
This work addressed a parameter optimization to simultaneously decrease the root mean square roughness $\left(R_{q}\right)$ as well as the thickness of the white layer (TW) and improve the material removal rate (MRR) for the wire electro-discharge machining (WEDM) of a stainless steel 304 (SS304). The factors considered are the discharge current (C), the gap voltage (VO), the pulse on time (POT), and the wire drum speed (SP). The interpolative radius basic function $(\mathrm{RBF})$ is applied to show the correlation between the varied factors and WEDM performances measured. The optimal selection is chosen using the multi-objective particle swarm optimization (MOPSO). Moreover, a traditional one using the response surface method (RSM) and desirability approach (DA) is adopted to compare the working efficiency of two optimization techniques. The results showed that the optimal findings of the C, POT, VO, and SP are $5.0 \mathrm{~A}, 1.0 \mu \mathrm{s}, 61.0 \mathrm{~V}$, and $8.0 \mathrm{~m} / \mathrm{min}$, respectively. The values of the $\mathrm{R}_{q}$ and TW are decreased by approximately $33.33 \%$ and $23.53 \%$, respectively, while the MRR enhances $47.42 \%$ at the optimal selection, as compared to the common values used. The BRF-MOPSO can provide better performance than the RSMDA.
\end{abstract}

Keywords: WEDM, white layer, root mean square roughness, material removal rate, RBF, stainless steel.

\section{INTRODUCTION}

Wire electro-discharge machining (WEDM) is an efficient method, which is used to produce complicated products with high accuracy and quality. WEDM processes are widely applied in manufacturing conductive materials like titanium, copper, aluminum, graphite, tool steel, and polycrystalline diamond (PCD). In this process, the high energy intensity is used to cut and vaporize the specimen in the high-temperature environment,

(c) 2020 Vietnam Academy of Science and Technology 
which causes the defects on the machined surface, such as high surface roughness, tensile residual stresses, recast layers, and cracks. Therefore, improving technological performances in the WEDM process is an urgent demand and an important research area.

The impacts of the inputs on the technical responses in the WEDM operation have been explored. The response surface model (RSM) was used to describe the variations of the thickness of the white layer (TW) regarding the pulse on time (POT), the wire offset (WO), and wire drum speed (SP). The authors stated that the explored correlation could be effectively adopted to estimate the objective outcome [1]. Similarly, the RSM technique was applied to design the correlated model of the average surface roughness $\left(\mathrm{R}_{a}\right)$ with respect to the POT, pulse off time (POFT), gap voltage (VO), and discharge current $(\mathrm{C})$ [2]. The findings revealed the proposed model ensured an acceptable precision. The genetic algorithm was used to decrease the $\mathrm{R}_{a}$ and TW for machining DIN 1.4542 [3]. The obtained reductions of the $\mathrm{R}_{a}$ and TW are $52 \%$ and $67 \%$, as compared to the common values used. Shabgard et al. developed a simulation model to calculate the $\mathrm{R}_{a}$, TW, and heat-affected zone (HAZ) [4]. The good agreement between simulated and experimental outcomes indicated the soundness of the simulation model. Shen et al. attempted to decrease the microscopic characteristics, such as the $\mathrm{R}_{a}$, TW, hardness $(\mathrm{MH})$, crack (MC), and void (MV) for the WEDM operation of Inconel 718 [5]. The primary outcomes revealed that the machined surface properties have been significantly enhanced with the aid of the high-speed EDM. Similarly, the Taguchi method was employed to decrease the $\mathrm{R}_{a}$, WEDM speed, and taper error (TE) for the tapper component [6]. The authors presented that the WEDM performances were primarily affected by the POT and tapper angle. The empirical correlations of the TW and the surface crack density (SCD) were proposed in terms of the POT, POFT, VO, and C, respectively [7]. The RSM was applied to minimize WEDM responses. The outcomes revealed that the WEDM responses were influenced by the POT, POFT, and CA, respectively. Additionally, the $\mathrm{R}_{a}$, one of the most important indicators of the surface integrity was optimized in conjunction with other factors, including the cutting speed (CS) [8], wire wear ratio (WWR) [9], kerf width (KW) [10-12], and material removal rate (MRR) [13-15].

As a result, the effects of the varied conditions on machining responses for different WEDM operations have been performed. Different optimization techniques, such as the RSM [1, 2, 4, 6-9, 13], Taguchi [3, 14], grey relation analysis (GRA) [15], and hybrid approach $[9,10,12]$ were utilized to resolve the optimizing issues. However, the published works regarding optimization in the WEDM performances have still the limitations.

The RSM was intensively applied to render the explored approximations between varied inputs and WEDM outputs. Additionally, different hybrid approaches, such as Taguchi-based methods, GRA, and hybrid approach were used to resolve the optimizing issues. However, the RSM formulations possess a low predictive precision due to the approximating characteristic [16]. The results selected directly from experimental data with the aid of the mentioned integrative methods may obtain the local optimization [17]. Therefore, it is an urgent requirement to suggest an efficient technique, which can be used to depict the nonlinear correlation between the varied inputs and WEDM performances. 
Additionally, most of the studies found in the literature aimed to decrease the $\mathrm{R}_{a}$ [1-15]. Practically, $\mathrm{R}_{q}$ is an important indicator of the roughness for the specific purpose of the machining case, which is necessary to address [18].

The selection of optimal factors to achieve a minimal $\mathrm{R}_{q}$ as well as $\mathrm{TW}$ and a maximal MRR for the WEDM process of a stainless steel has not been explored in the published works. The stainless steels are widely applied in the necessary parts of the aerospace, marine, automotive applications. However, it can be considered as a difficult-to-cut material that is affected by the work-hardening behavior; hence, low productivity and machined quality are obtained. Therefore, it is an urgent demand to develop efficient models, which effectively forecast the values of the $\mathrm{R}_{q}$, TW, and MRR for the WEDM of stainless steel. Furthermore, the determination of optimal factors for minimizing $\mathrm{R}_{q}$ as well as TW and maximizing MRR is still a significant impact in terms of improving the machining efficiency of the WEDM process.

To overcome these drawbacks, a prominent optimization technique combining the $\mathrm{RBF}$ correlation and MOPSO is proposed to treat the relation between the machined characteristics ( $\mathrm{R}_{q}$ and TW) and efficiency (MRR) of the WEDM process of stainless steel. The interpolation-based RBF correlations are used to model the WEDM performances. The optimal process inputs and outputs are generated using the MOPSO. A hybrid approach is expected as a significant approach to generate reliable outcomes, as compared to the conventional one.

\section{OPTIMIZATION APPROACH}

The systematical approach depicted in Fig. 1 is employed to obtain optimal inputs, as listed as below:

- The machining trials are performed to generate the WEDM experimental data using the Box-Behnken design method (BBDM) [19]. In this method, each varied factor has equal three levels and treated combinations are laid on the edge and at the center. The detail of the BBDM can be explored in the work of [20].

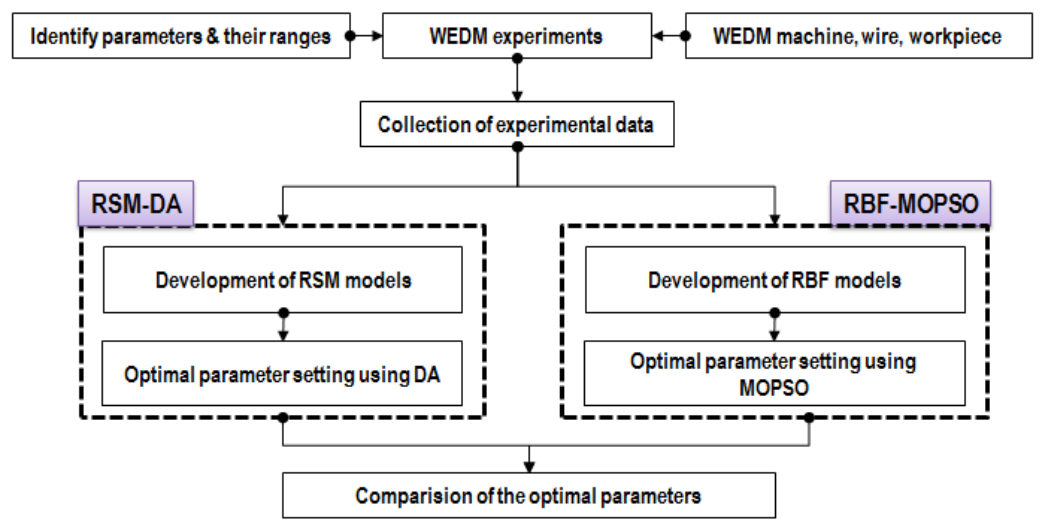

Fig. 1. Optimizing steps for the WEDM operation 
- The RBF model is used to depict the correlation between WEDM inputs and performances. For the RBF correlations, the radial basis function is the active approximation. The output is a complex combination of the radial and linear units. The primary advantages of the RBF models are fast training, compact system, and high computational efficiency [21]. The interpolative RBF correlations are intensively applied in the approximation of nonlinear data. The RBF approximation is presented using Eq. (1)

$$
F(x)=\sum_{i=1}^{n} \lambda_{i} \phi\left(\left\|x-x_{i}\right\|\right)+b x+c,
$$

where $\lambda_{i}, b$, and $c$ variables are determined using Eqs. (2) and (3)

$$
\begin{gathered}
{\left[\begin{array}{cc}
\phi & P \\
P^{T} & 0
\end{array}\right]\left\{\begin{array}{c}
\lambda \\
a
\end{array}\right\}=\left\{\begin{array}{c}
F \\
0
\end{array}\right\},} \\
P=\left\{\begin{array}{cc}
1 & X_{1}^{T} \\
1 & X_{2}^{T} \\
\cdot & \cdot \\
\cdot & \cdot \\
\cdot & \cdot \\
1 & X_{n}^{T}
\end{array}\right\}, \lambda=\left\{\begin{array}{c}
\lambda_{1} \\
\lambda_{2} \\
\cdot \\
\cdot \\
\cdot \\
\lambda_{n}
\end{array}\right\}, a=\left\{\begin{array}{c}
c \\
b_{2} \\
\cdot \\
\cdot \\
\cdot \\
b_{d}
\end{array}\right\}, b=\left\{\begin{array}{c}
b_{1} \\
b_{2} \\
\cdot \\
\cdot \\
\cdot \\
b_{d}
\end{array}\right\}, F=\left\{\begin{array}{c}
f\left(x_{1}\right) \\
f\left(x_{2}\right) \\
\cdot \\
\cdot \\
\cdot \\
f\left(x_{n}\right)
\end{array}\right\},
\end{gathered}
$$

where $\phi$ and $d$ are the $n \times n$ matrix and the dimension of vector $x$.

- The optimal factors are selected using the MOPSO. The MOPSO is an evolution technique to find the optimal solution based on the searching behavior of the food of birds or fishes. The updated velocity and locations are selected in the processing time using the obtained optimum points of the former and entire particles. The new velocity and position are generated using the following rules

$$
\begin{aligned}
& v_{i d}(t+1)=\omega v_{i d}(t)+r_{1} c_{1}\left(p_{i d}-x_{i d}(t)\right)+r_{2} c_{2}\left(g_{d}-x_{i d}(t),\right. \\
& x_{i d}(t+1)=x_{i d}(t)+v_{i d}(t+1) .
\end{aligned}
$$

The detail of the operating procedure of the MOPSO can be inferred in the work of [17]. Consequently, it is unnecessary to present in this work. Many former investigators have indicated that the MOPSO is a prominent solution to achieve a reliable global point $[17,22,23]$. The implementations of the RBF models and the MOPSO are performed using the Isight 5.8 software.

- A traditional approach using the RSM and desirability approach (DA) is applied to select the optimal inputs. The detail of the RSM and DA can be assessed in the publication of $[2,8]$.

- The effectiveness of the two optimization techniques is assessed using the optimal results.

In this paper, three EDM responses measured, including the $\mathrm{R}_{q}$, the $\mathrm{TW}$, and the MRR are optimized using the interpolative RBF models and MOPSO. The TW value is estimated using Eq. (6)

$$
T W=\frac{1}{15} \sum_{i=1}^{15} T W_{i},
$$


where $T W_{i}$ is the thickness of the white layer at the $i^{t h}$ point measured. The material removal rate $\left(\mathrm{mm}^{3} / \mathrm{min}\right)$ is calculated using Eq. (7)

$$
M R R=\frac{A * W * B}{t_{W E D M}}
$$

where $A(\mathrm{~mm}), W(\mathrm{~mm}), B(\mathrm{~mm})$, and $t_{W E D M}(\mathrm{~min})$ are the machined length, the width of the machined groove, the thickness of the specimen, and the eroded time, respectively.

Four varied factors, including the current (C), voltage (VO), pulse on time (POT), and wire - speed (SP) as well as their ranges are depicted in Tab. 1. The parameter levels are recommended based on the characteristics of the machine tool as well as the wire and material properties. Tab. 2 shows the chemical composition of the SS 304.

Table 1. Considered factors

\begin{tabular}{clccc}
\hline Symbol & \multicolumn{1}{c}{ Parameters } & Level -1 & level 0 & level +1 \\
\hline C & Discharge current $(\mathrm{A})$ & 2 & 6 & 10 \\
POT & Pulse on time $(\mu \mathrm{s})$ & 1 & 3 & 5 \\
VO & Gap voltage $(\mathrm{V})$ & 20 & 50 & 80 \\
SP & Wire drum speed $(\mathrm{m} / \mathrm{min})$ & 4 & 6 & 8 \\
\hline
\end{tabular}

Table 2. Chemical composition of a stainless steel 304

\begin{tabular}{cccccccc}
\hline $\mathrm{C}$ & $\mathrm{Mn}$ & $\mathrm{P}$ & $\mathrm{S}$ & $\mathrm{Si}$ & $\mathrm{Cr}$ & $\mathrm{Ni}$ & $\mathrm{Al}$ \\
\hline 0.08 & 2.00 & 0.045 & 0.03 & 0.75 & 19.00 & 10.00 & 0.10 \\
\hline
\end{tabular}

\section{EXPERIMENTALS AND MEASUREMENTS}

The machine entitled MTL-SFL70 is used to perform the WEDM experiments. The molybdenum wire having a diameter of $0.18 \mathrm{~mm}$ is used as the cutting tool. A new wire is replaced for each trial to ensure the machining accuracy. A plate of stainless steel having the dimensions of $230 \mathrm{~mm} \times 90 \mathrm{~mm} \times 8 \mathrm{~mm}$ is used to perform the WEDM runs (Fig. 2). A sample with a cutting length of $30 \mathrm{~mm}$ is processed for each trial. A roughness tester, namely Mitutoyo SJ-301 is used to measure the values of the $\mathrm{R}_{q}$ at five positions. The values of the TW are analyzed with the aid of a microscopy entitled Carl Zeiss 37081. The measured values of the TW at the varied inputs are shown in Fig. 3. The roughness profiles are exhibited in Fig. 4. The experimental results of the WEDM trials are exhibited in Tab. 3. 


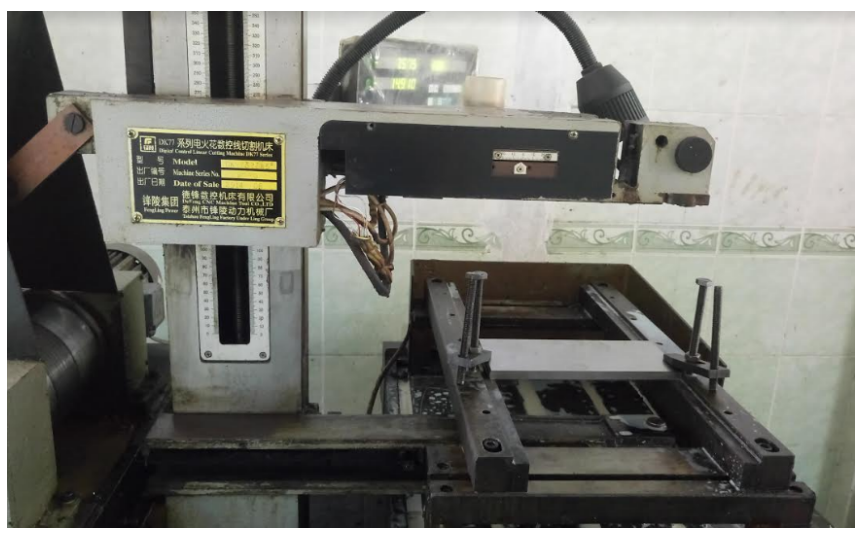

(a) Experimental setting

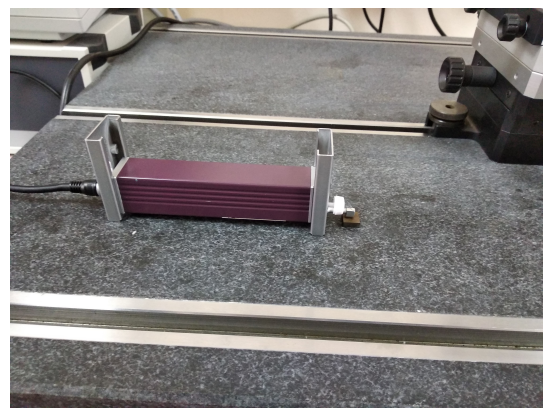

(c) Measuring roughness

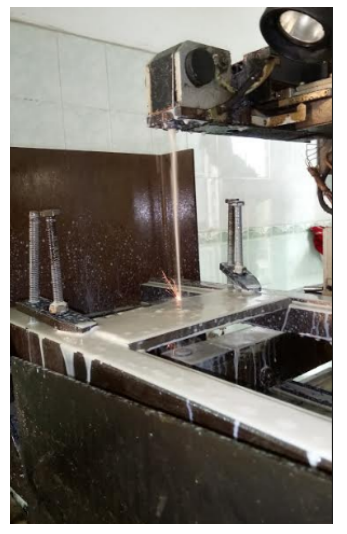

(b) Performing experiment

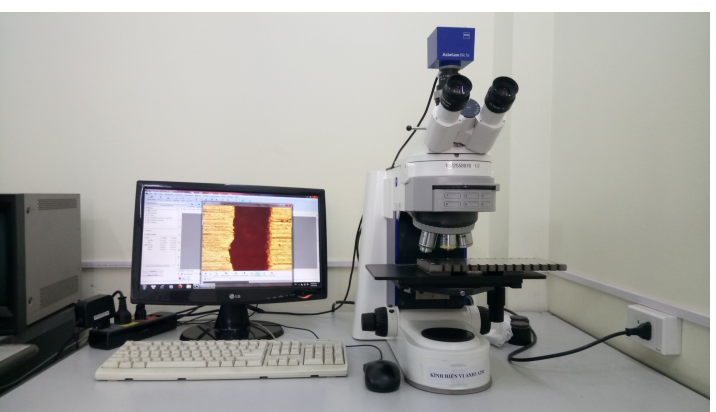

(d) Measuring white layer

Fig. 2. WEDM experiments and measuring data

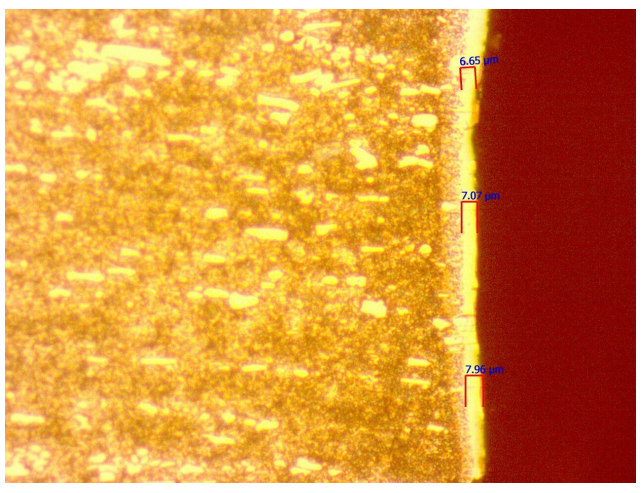

(a) TW at the $\mathrm{C}=2.0(\mathrm{~A})$, POT $=3.0(\mu \mathrm{s})$, $\mathrm{VO}=50.0(\mathrm{~V})$, and $\mathrm{SP}=8.0(\mathrm{~m} / \mathrm{min})$

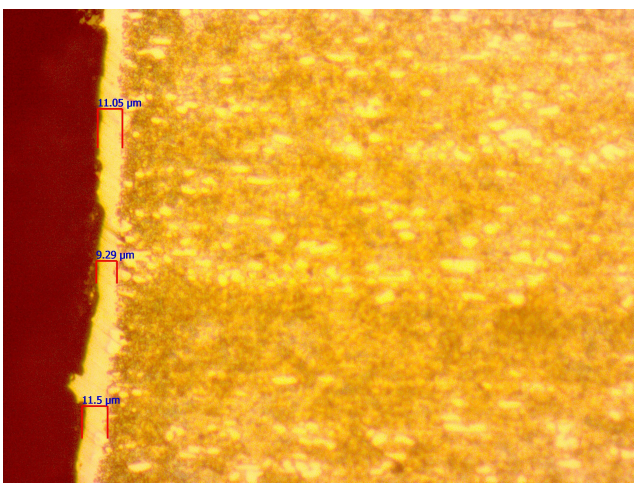

(b) TW at the $\mathrm{C}=10.0(\mathrm{~A}), \mathrm{POT}=3.0(\mu \mathrm{s})$, $\mathrm{VO}=50.0(\mathrm{~V})$, and $\mathrm{SP}=8.0(\mathrm{~m} / \mathrm{min})$

Fig. 3. The representative values of the TW 


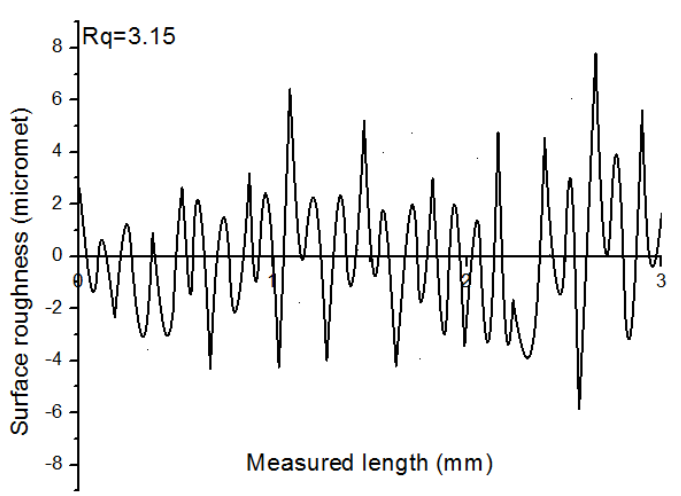

(a) $\mathrm{R}_{q}$ at the $\mathrm{C}=6.0(\mathrm{~A}), \mathrm{POT}=3.0(\mu \mathrm{s}), \mathrm{VO}=$ $20.0(\mathrm{~V})$, and $\mathrm{SP}=4.0(\mathrm{~m} / \mathrm{min})$

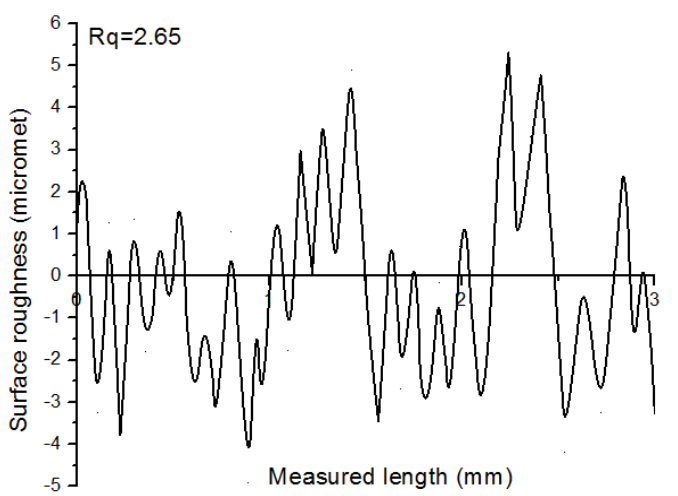

(b) $\mathrm{R}_{q}$ at the $\mathrm{C}=6.0(\mathrm{~A}), \mathrm{POT}=1.0(\mu \mathrm{s}), \mathrm{VO}=$ $50.0(\mathrm{~V})$, and $\mathrm{SP}=4.0(\mathrm{~m} / \mathrm{min})$

Fig. 4. The representative values of the $\mathrm{R}_{q}$

Table 3. Experimental results

\begin{tabular}{cccccccc}
\hline No. & $\mathrm{C}(\mathrm{A})$ & $\mathrm{POT}(\mu \mathrm{s})$ & $\mathrm{VO}(\mathrm{V})$ & $\mathrm{SP}(\mathrm{m} / \mathrm{min})$ & $\mathrm{R}_{q}(\mu \mathrm{m})$ & $\mathrm{TW}(\mu \mathrm{m})$ & $\mathrm{MRR}\left(\mathrm{mm}^{3} / \mathrm{min}\right)$ \\
\hline 1 & 2 & 3 & 80 & 6 & 5.64 & 11.74 & 7.3266 \\
2 & 6 & 1 & 20 & 6 & 3.24 & 6.46 & 5.7972 \\
3 & 10 & 3 & 80 & 6 & 7.85 & 16.07 & 7.8748 \\
4 & 6 & 5 & 50 & 8 & 4.26 & 10.98 & 9.1643 \\
5 & 6 & 3 & 50 & 6 & 4.78 & 9.81 & 6.0540 \\
6 & 6 & 3 & 80 & 4 & 5.14 & 10.94 & 6.6698 \\
7 & 6 & 3 & 20 & 4 & 3.14 & 5.87 & 5.5436 \\
8 & 10 & 1 & 50 & 6 & 5.02 & 11.72 & 5.9720 \\
9 & 6 & 1 & 50 & 8 & 2.92 & 7.68 & 6.7106 \\
10 & 10 & 3 & 50 & 4 & 5.18 & 11.54 & 5.8892 \\
11 & 6 & 1 & 50 & 4 & 2.64 & 6.71 & 4.7851 \\
12 & 2 & 3 & 50 & 4 & 2.98 & 6.32 & 5.3725 \\
13 & 6 & 1 & 80 & 6 & 5.24 & 12.54 & 6.5439 \\
14 & 2 & 5 & 50 & 6 & 4.34 & 10.54 & 7.6245 \\
15 & 2 & 1 & 50 & 6 & 2.82 & 7.26 & 5.1629 \\
16 & 6 & 5 & 20 & 6 & 4.76 & 9.76 & 7.8071 \\
17 & 2 & 3 & 20 & 6 & 3.64 & 6.54 & 5.8200 \\
18 & 10 & 3 & 50 & 8 & 5.51 & 12.32 & 7.9305 \\
19 & 6 & 3 & 50 & 6 & 4.77 & 9.86 & 6.0320 \\
20 & 6 & 3 & 20 & 8 & 3.44 & 7.22 & 7.5083 \\
21 & 6 & 5 & 80 & 6 & 6.78 & 15.82 & 9.3578 \\
22 & 2 & 3 & 50 & 8 & 3.34 & 7.24 & 7.0265 \\
23 & 10 & 3 & 20 & 6 & 5.82 & 10.54 & 6.6553 \\
24 & 10 & 5 & 50 & 6 & 6.54 & 15.08 & 8.1948 \\
25 & 6 & 3 & 80 & 8 & 5.44 & 11.18 & 8.8055 \\
26 & 6 & 5 & 50 & 4 & 3.19 & 11.74 & 6.9546 \\
\hline
\end{tabular}




\section{RESULTS AND DISCUSSIONS}

\subsection{The impacts of the varied factors}

The $\mathrm{R}^{2}$ value is an evaluation indicator, which is adopted to explore the predictive precision of the interpolative RBF models. The $\mathrm{R}^{2}$-values of the $\mathrm{R}_{q}, \mathrm{TW}$, and MRR are $0.9919,0.9867$, and 0.9917 , respectively, presenting high agreements between the experimental and forecasted values (Fig. 5). The approximating errors (root mean square errorRMSE, max absolute error-MAE, and average absolute error-AAE) are very small, proving the soundness of the models developed.

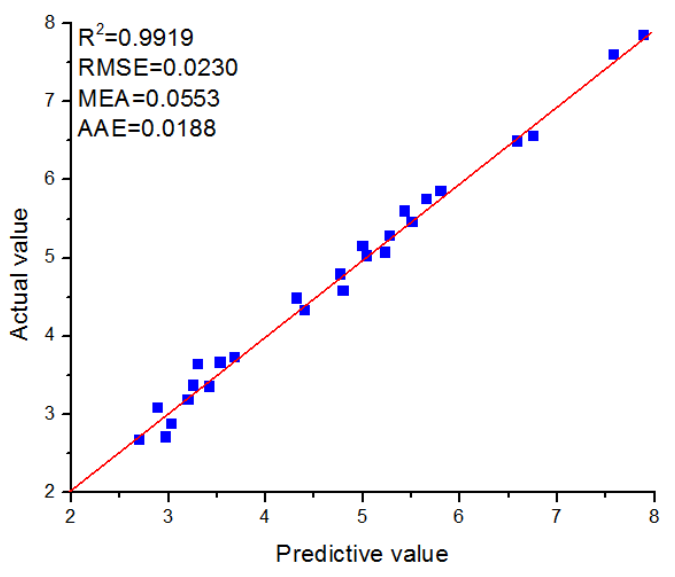

(a) For the RBF model of the $\mathrm{R}_{q}$

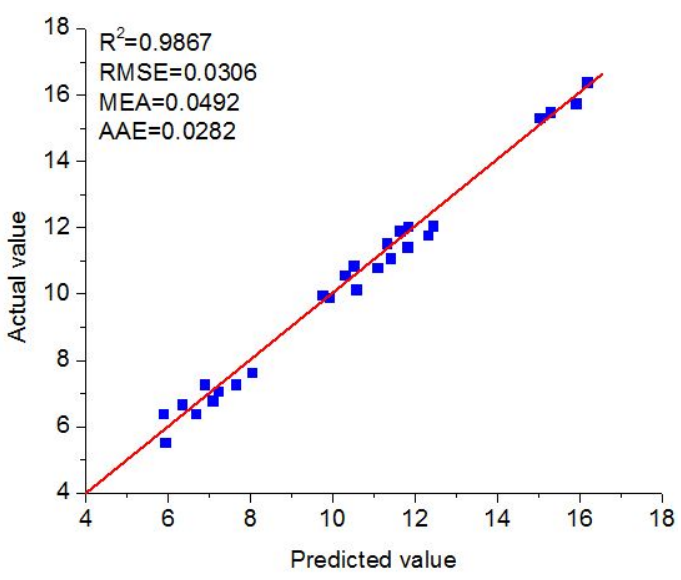

(b) For the RBF model of the TW

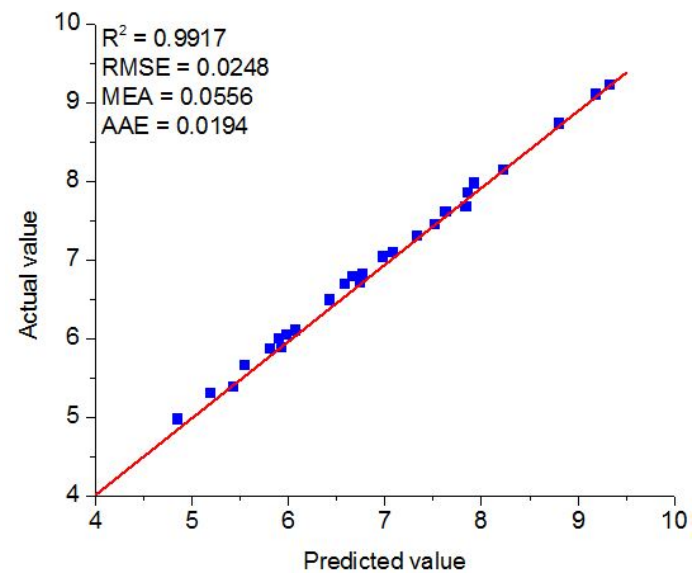

(c) For the RBF model of the MRR

Fig. 5. Assessment of the precision of the RBF correlations

In the WEDM operation, the $\mathrm{R}_{q}$ is expressed as the changes in the resulting roughness under the effects of the varied inputs and a low $\mathrm{R}_{q}$ is preferred. Fig. 6 exhibits the 
influences of varied parameters on the $\mathrm{R}_{q}$. An increment in the $\mathrm{R}_{q}$ is found with an increased VO and/or C (Fig. 6(a)). Low energy intensity is produced at a low VO and/or $\mathrm{C}$ and a small amount of material is melt and evaporated. The particle having a small size is consequently removed from the workpiece surface, which has an effective contribution to the reduction in the roughness. A further increment in the $\mathrm{C}$ and/or VO causes a higher spark and more material in the specimen is melted and vaporized. Obviously, the bigger holes and deeper craters are obtained in the WEDM surface; hence, a higher roughness is produced. The $R_{q}$ is increased by $53.63 \%$ when the $C$ changed from 2.0 to $10.0 \mathrm{~A}$. The $\mathrm{R}_{q}$ is increased by $46.03 \%$ when the VO increased from 20.0 to $80.0 \mathrm{~V}$.

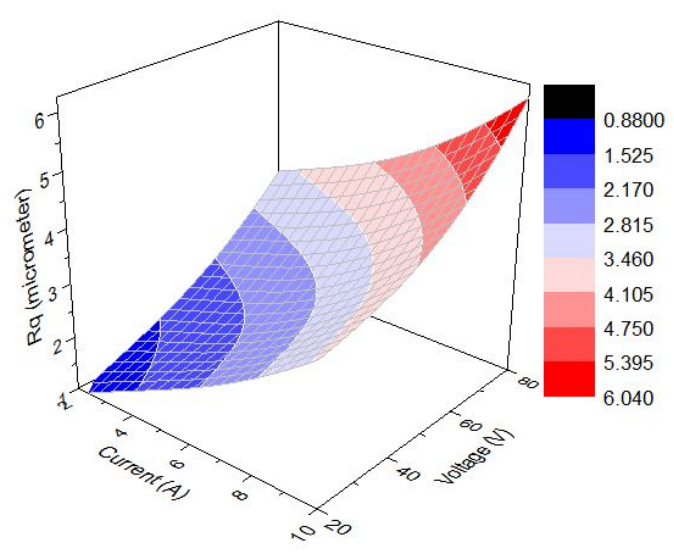

(a) $\mathrm{R}_{q}$ versus voltage and current (pulse of time $=$ $3 \mu \mathrm{s}$ and wire speed $=6 \mathrm{~m} / \mathrm{min}$ )

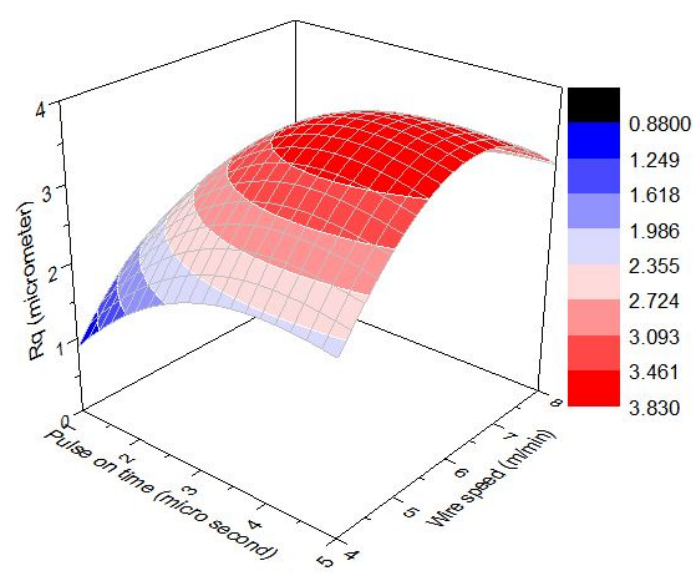

(b) $\mathrm{R}_{q}$ versus pulse of time and wire speed (voltage $=20 \mathrm{~V}$ and current $=6 \mathrm{~A}$ )

Fig. 6. Impacts of varied parameters on the $\mathrm{R}_{q}$

The increased $\mathrm{R}_{q}$ is found with an increment in the SP and/or POT (Fig. 6(b)). After the maximum point, a further increment in the SP causes a reduction in the roughness. A low SP leads to a low thermal energy intensity, which has less impact on material removal. A small amount of material is vaporized from the specimen; hence a smooth WEDM surface having small holes and/or craters is generated. An increment in the washout is obtained with an increased SP. Higher spark intensity is produced and rapidly occurred on the machined surface. Therefore, a coarse surface is produced at a high SP. Fortunately, excessive SP results in a reduction in roughness. A further value of the SP may cause the even appearance of the WEDM spark, which decreases the profile irregularity; hence a better roughness is obtained.

Similarly, a higher POT leads to an increment in the WEDM spark, which causes an increased evaporation of the material. The particle having a larger size is removed from the machined surface and the deviation of the profile irregularity is increased. The bigger holes and craters are produced and the roughness is increased. The $\mathrm{R}_{q}$ is increased by $36.44 \%$ when the POT increased from 1.0 to $5.0 \mu \mathrm{s}$. 
In the WEDM operation, the TW is expressed as the changes in the thickness of the white layer under the effects of the varied inputs and a low TW is desirable. Fig. 7 exhibits the influences of varied parameters on the TW. An increment in the TW is found with an increased $\mathrm{VO}$ and/or C (Fig. 6(a)). At a higher value of the $\mathrm{C}$ or $\mathrm{VO}$, the higher WEDM spark generated increases more molten and vaporized material. A high amount of material on the workpiece surface is affected by the thermal energy. The molten material is solidified on the machined surface, which causes not only a larger molten zone but also deeper molten depth. The TW is increased by $55.29 \%$ when the $C$ changed from 2.0 to $10.0 \mathrm{~A}$. The TW is increased by $69.27 \%$ when the VO increased from 20.0 to $80.0 \mathrm{~V}$.

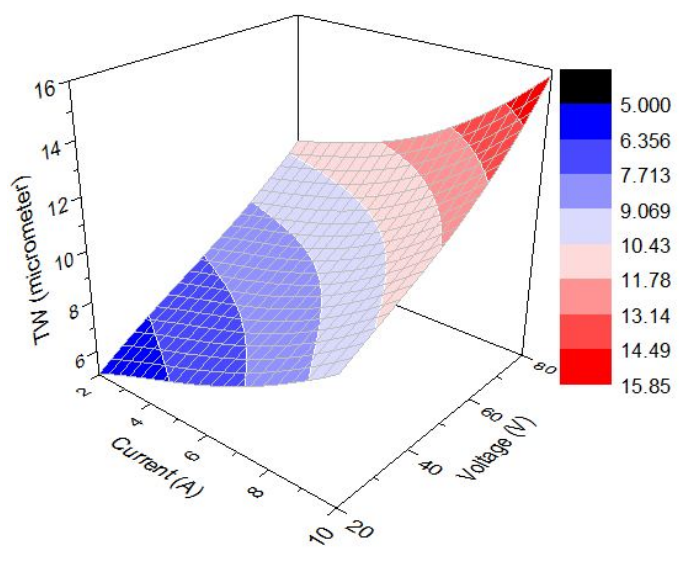

(a) TW versus voltage and current (pulse of time $=3 \mu \mathrm{s}$ and wire speed $=6 \mathrm{~m} / \mathrm{min}$ )

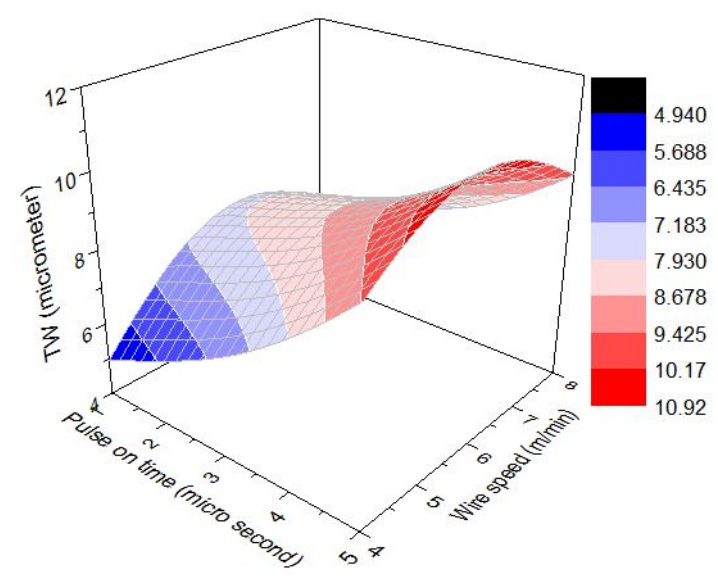

(b) TW versus pulse of time and wire speed (voltage $=20 \mathrm{~V}$ and current $=6 \mathrm{~A}$ )

Fig. 7. Impacts of varied parameters on the TW

The increased TW is found with an increment in the SP and/or POT (Fig. 7(b)). After the maximum point, a further increment in the SP causes a reduction in the TW. A longer POT causes more heat that transfers to the workpiece. The excessive molten material is solidified on the machined surface and a higher thickness of the recast layer is produced. The TW is increased by $41.03 \%$ when the POT increased from 1.0 to $5.0 \mu \mathrm{s}$.

An increased SP causes the rapid occurrence of the sparks in the machined surface. Higher thermal energy is used to melt and generate higher evaporation of material. Therefore, more molten material is produced and deposited on the WEDM surface; hence a thicker TW is obtained. A further SP may have a significant contribution to the flushing of the debris. A higher amount of the debris is effectively flushed out from the WEDM surface; hence, a lower TW is obtained.

The WEDM surfaces at different varied conditions are depicted in Fig. 8. A high surface quality with small holes, cracks, and craters is produced at a low current (Fig. 8(a)). A coarse surface having bigger holes, craters, and cracks are obtained at high current (Fig. 8(b)). 


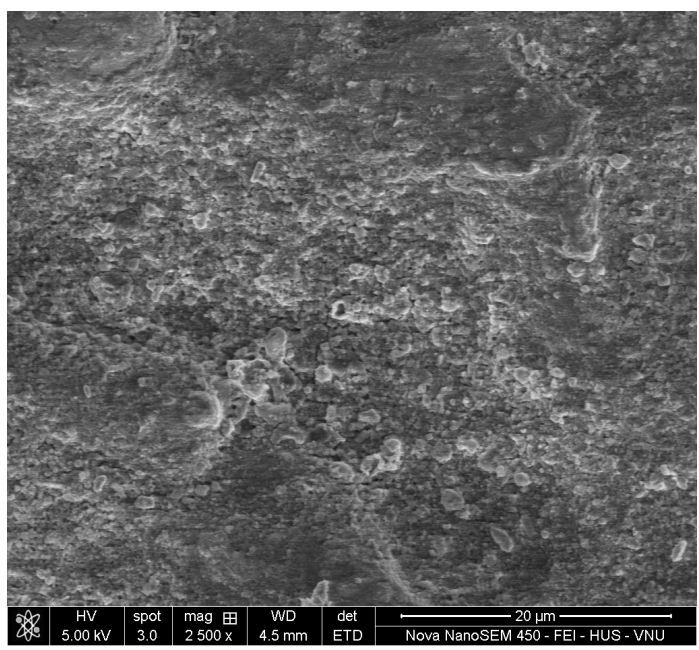

(a) Surface at the $\mathrm{C}=2(\mathrm{~A}), \mathrm{POT}=3.0(\mu \mathrm{s}), \mathrm{VO}=$ $50.0(\mathrm{~V})$, and $\mathrm{SP}=8.0(\mathrm{~m} / \mathrm{min})$

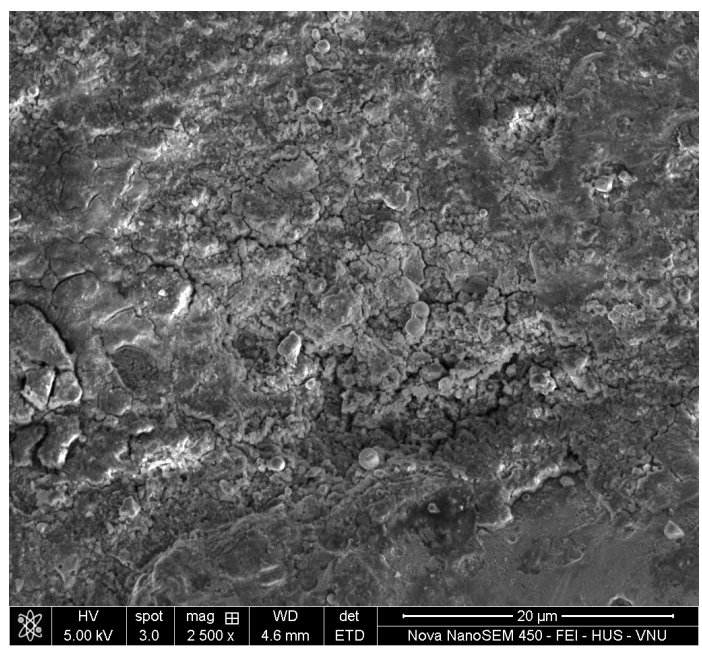

(b) Surface at the $\mathrm{C}=10(\mathrm{~A}), \mathrm{POT}=3.0(\mu \mathrm{s}), \mathrm{VO}=$ $50.0(\mathrm{~V})$, and $\mathrm{SP}=8.0(\mathrm{~m} / \mathrm{min})$

Fig. 8. WEDM surface at the varied conditions

In the WEDM operation, higher MRR values are preferred to increase evaporating efficiency. The influences of the varied inputs on the MRR are exhibited in Fig. 9. Generally, the material removal rate is improved with an increased C, VO, POT, and SP. With an increase in the input from the lowest and highest value, the material removal rate impressively increases. Fig. 9(a) indicates that the MRR values increase in parallel to an increased $\mathrm{C}$ and/or VO. When a higher $\mathrm{C}$ and/or VO apply, the increased electrical spark

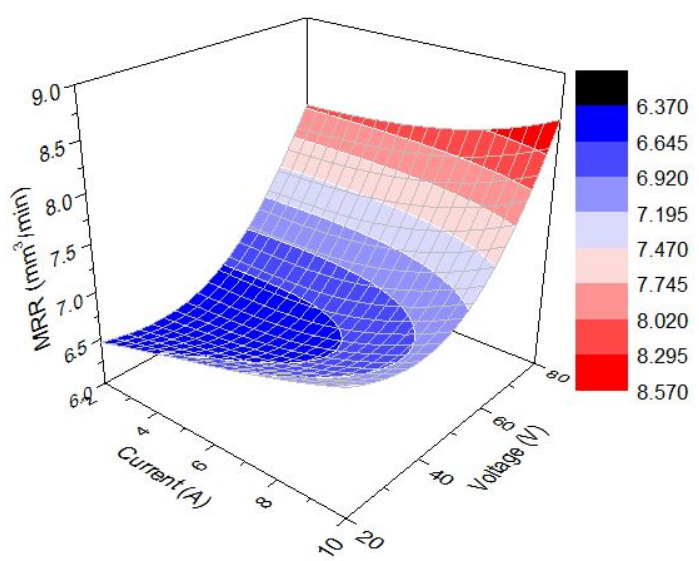

(a) MRR versus voltage and current (pulse of time $=3 \mu \mathrm{s}$ and wire speed $=6 \mathrm{~m} / \mathrm{min}$ )

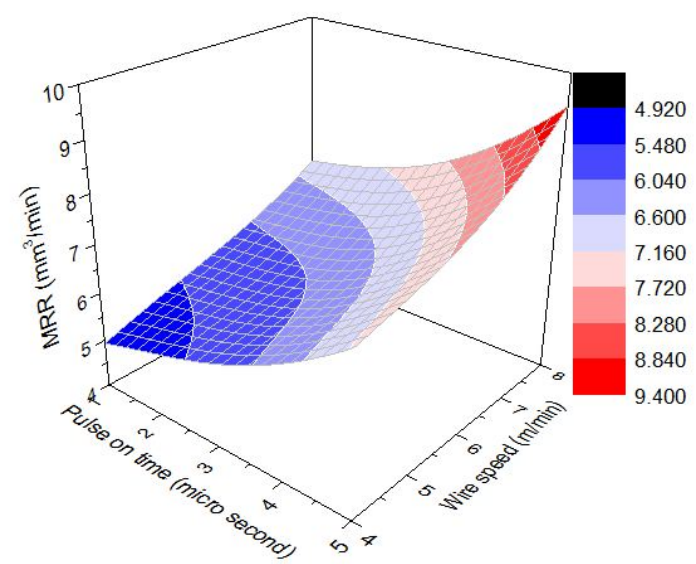

(b) MRR versus pulse of time and wire speed (voltage $=20 \mathrm{~V}$ and current $=6 \mathrm{~A}$ )

Fig. 9. Impacts of varied parameters on the MRR 
causes more melted and evaporated material. Therefore, a higher amount of material is removed. The MRR value is enhanced by $11.94 \%$ when the $\mathrm{C}$ increased from 2.0 to $8.0 \mathrm{~A}$. The MRR value is enhanced by $20.09 \%$ when the VO increased from 20.0 to $80.0 \mathrm{~V}$.

At a higher value of the POT, higher discharge energy generated; hence more material is melted and evaporated (Fig. 9(b)). Therefore, a higher amount of material is processed and the evaporating productivity is enhanced. The MRR value is enhanced by $43.49 \%$ when the POT increased from 1.0 to $5.0 \mu \mathrm{s}$. The similar effect of the SP on the MRR can be found in Fig. 9(b). The MRR value is enhanced by $36.93 \%$ when the SP increased from 4.0 to $8.0 \mathrm{~m} / \mathrm{min}$.

The ANOVA analysis having a confidence level of $95 \%$ is used to analyze the contributions of the process inputs. The varied factor having a $p$-value less than 0.05 is listed as the effective term. The varied factor having the $p$-value greater than 0.05 is considered as an insignificant input.

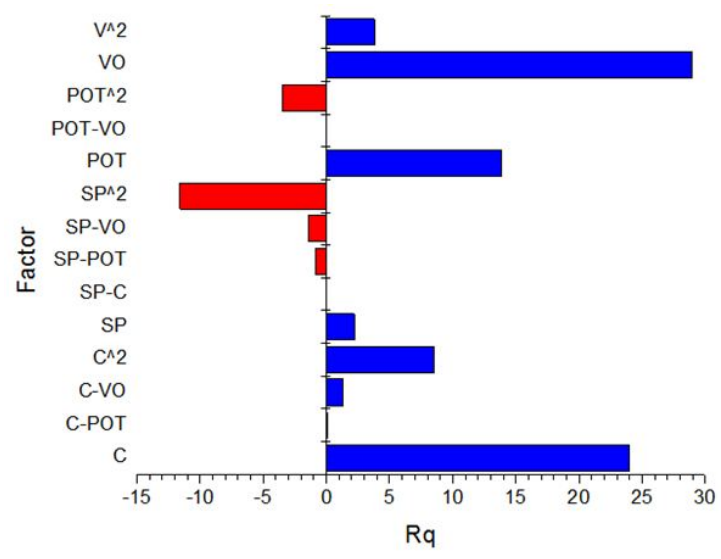

(a) The contributions of the processing conditions for $\mathrm{R}_{q}$

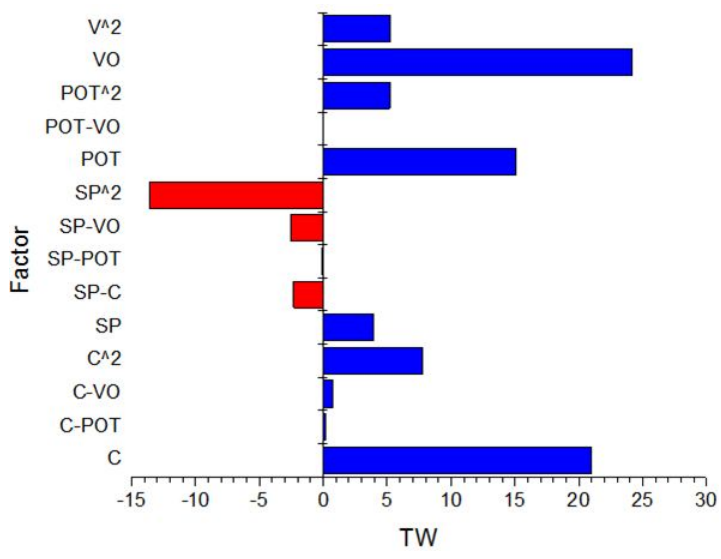

(b) The contributions of the processing conditions for TW

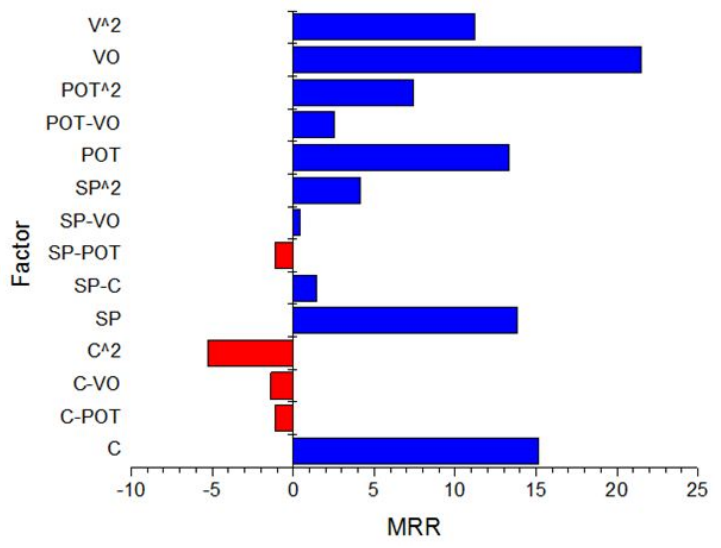

(c) The contributions of the processing conditions for MRR

Fig. 10. Parameters' contributions 
The contributed percentage of the varied factors for the $\mathrm{R}_{q}$ is illustrated in Fig. 10(a). The $\mathrm{VO}$ is the most effective term $(28.92 \%)$, followed by C $(23.96 \%)$, POT $(13.82 \%)$, and $\mathrm{SP}(2.21 \%)$. Especially, $\mathrm{SP}^{2}$ is the highest quadratic term $(11.61 \%)$, followed by $\mathrm{C}^{2}(8.57 \%)$, $\mathrm{VO}^{2}(3.79 \%)$, and $\mathrm{POT}^{2}(3.49 \%)$.

The contributed percentage of the varied factors for the TW is illustrated in Fig. 10(b). The VO is the most affected term with the contribution of $24.19 \%$, followed by C $(20.96 \%)$, POT (15.08\%), and SP (3.92\%). The $\mathrm{SP}^{2}$ has an effective effect on the TW with the highest percentage of $13.63 \%$, followed by $\mathrm{CO}^{2}(7.80 \%), \mathrm{VO}^{2}(5.26 \%)$, and $\mathrm{POT}^{2}(5.20 \%)$.

The contributed percentage of the varied factors for the MRR is illustrated in Fig. 10(c). The explored contributions of the VO, C, SP, and POT are 21.51\%, 15.12\%, $13.86 \%$, and $13.34 \%$, respectively. The $\mathrm{VO}^{2}$ has the greatest contribution to the quadratic factor $(11.24 \%)$. This is followed by POT $^{2}(7.42 \%), \mathrm{C}^{2}(5.24 \%)$, and $\mathrm{SP}^{2}(4.15 \%)$.

\subsection{Optimization results of the varied factors and WEDM responses}

The optimal selection is determined using the interpolative RBF correlations and the MOPSO. The graphs generated by the MOPSO are exhibited in Fig. 11, in which the point no. 522 is a proper selection. Tab. 4 presents the optimum outcomes of the varied factors and objectives. The reductions in the $\mathrm{R}_{q}$ and TW are $33.3 \%$ and $23.53 \%$, respectively, while the MRR improves by $47.42 \%$ in comparison with the common values used.

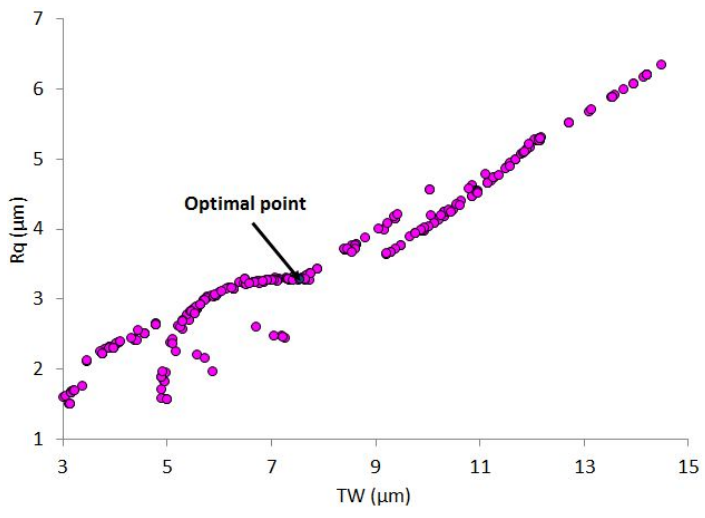

(a) $R_{q}$ versus TW

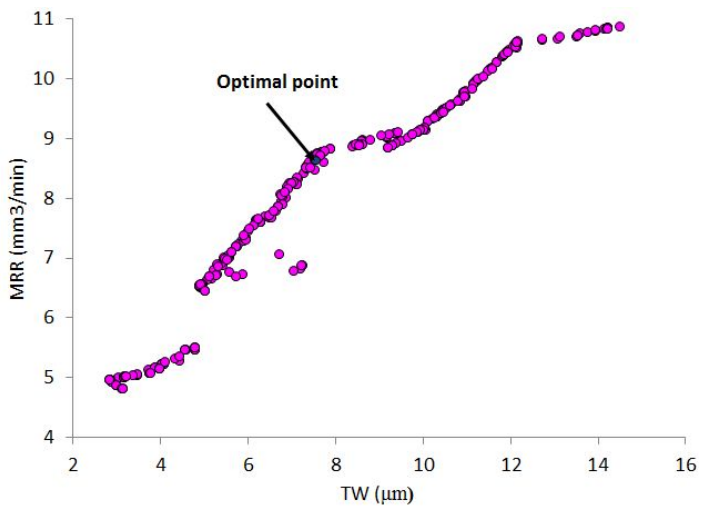

(b) MRR versus TW

Fig. 11. Pareto fonts generated by MOPSO

Table 4. Optimization results generated by RBF-MOPSO

\begin{tabular}{lccccccc}
\hline & \multicolumn{4}{c}{ Optimization parameters } & \multicolumn{3}{c}{ Responses } \\
\cline { 2 - 8 } \multicolumn{1}{c}{ Method } & $\mathrm{C}$ & POT & VO & $\begin{array}{c}\mathrm{SP} \\
(\mathrm{m} / \mathrm{min})\end{array}$ & $\begin{array}{c}\mathrm{R}_{q} \\
(\mu \mathrm{m})\end{array}$ & $\begin{array}{c}\mathrm{TW} \\
(\mu \mathrm{m})\end{array}$ & $\begin{array}{c}\mathrm{MRR} \\
\left(\mathrm{mm}^{3} / \mathrm{min}\right)\end{array}$ \\
\hline Initial & 6.0 & 3.0 & 50.0 & 6.0 & 4.77 & 9.86 & 6.0320 \\
RBF-MOPSO & 5.0 & 1.0 & 61.0 & 8.0 & 3.18 & 7.54 & 8.8925 \\
Improvement (\%) & & & & & 33.33 & 23.53 & 47.42 \\
\hline
\end{tabular}


The mathematical models of the $\mathrm{R}_{q}$, TW, and MRR generated by the RSM are expressed as

$$
\begin{aligned}
R_{q}=- & 7.00497-0.031771 C+0.71500 P O T+0.03299 V O+3.04625 S P \\
+ & 0.00006 C V O-0.00094 C A S P+0.00008 P O T V O+0.04938 P O T S P \\
+ & 0.0257 C^{2}-0.11375 P O T^{2}+0.00066 V O^{2}-0.25656 S P^{2} \\
T W= & -12.31674-0.030625 C+0.47083 P O T+0.05596 V O+4.80396 S P \\
+ & 0.0025 C P O T+0.00068 C V O-0.00438 C S P-0.00008 P O T V O \\
- & 0.10812 P O T S P-0.00463 V S P+0.04922 C^{2}+0.1775 P O T^{2} \\
+ & 0.00056 V O^{2}-0.33969 S P^{2} \\
M R R= & +7.58714-0.04369 C-0.46617 P O T-0.07393 V O-0.67296 S P \\
& -0.00746 C P O T-0.00059 C V O+0.0121 C S P+0.00335 P O T V O \\
& +0.01776 P O T S P+0.00071 V O S P+0.00921 C^{2}+0.13761 P O T^{2} \\
& +0.00084 V O^{2}+0.08404 S P^{2} .
\end{aligned}
$$

The $\mathrm{R}^{2}$ value is adopted to explore the adequacy of the developed regressions. The $\mathrm{R}^{2}$-values of the $\mathrm{R}_{q}$, TW, and MRR are $0.9572,0.9587$, and 0.9612 , denoting an acceptable correlation between experimental and predicted data. Consequently, the developed regressions can be applied in the optimizing step. The DA is used to select the optimal inputs, as shown in Tab. 5. The optimal values of the C, POT, VO, and SP are $2.0 \mathrm{~A}, 5.0 \mu \mathrm{s}$, $20.0 \mathrm{~V}$, and $8.0 \mathrm{~m} / \mathrm{min}$. The values of the $\mathrm{R}_{q}$, TW, and MRR are $3.28 \mu \mathrm{m}, 7.56 \mu \mathrm{m}$, and $8.7478 \mathrm{~mm}^{3} / \mathrm{min}$ (Fig. 12).

Table 5. Optimization results generated by RSM-DA

\begin{tabular}{lccccccc}
\hline & \multicolumn{4}{c}{ Optimization parameters } & \multicolumn{3}{c}{ Responses } \\
\cline { 2 - 8 } \multicolumn{1}{c}{ Method } & $\mathrm{C}$ & POT & VO & SP & $\mathrm{R}_{q}$ & TW & $\begin{array}{c}\text { MRR } \\
\end{array}$ \\
& $(\mathrm{A})$ & $(\mu \mathrm{s})$ & $(\mathrm{V})$ & $(\mathrm{m} / \mathrm{min})$ & $(\mu \mathrm{m})$ & $(\mu \mathrm{m})$ & $\left(\mathrm{mm}^{3} / \mathrm{min}\right)$ \\
\hline Initial & 6.0 & 3.0 & 50.0 & 6.0 & 4.77 & 9.86 & 6.0320 \\
RSM-DA & 2.0 & 5.0 & 20.0 & 8.0 & 3.29 & 7.57 & 8.7478 \\
Improvement (\%) & & & & & 31.24 & 23.33 & 45.02 \\
\hline
\end{tabular}

The improvements in the $\mathrm{R}_{q}$, TW, and MRR generated by the RBF-MOPSO are higher than the RSM-DA due to the selection of the global solution. It can be stated that the RBFMOPSO can be used to generate a reliable solution, as compared to the RSM-DA.

In this paper, a combined optimization technique using the RBF model and MOPSO is proposed to select the optimal process inputs for minimal $\mathrm{R}_{q}$ as well as TW and maximize MRR of the WEDM process of stainless. The relation between the economic aspect (MRR) and the social aspect ( $\mathrm{R}_{q}$ and TW) of the WEDM process is addressed. The prediction of the WEDM responses measured can be implemented using the RBF correlations. 

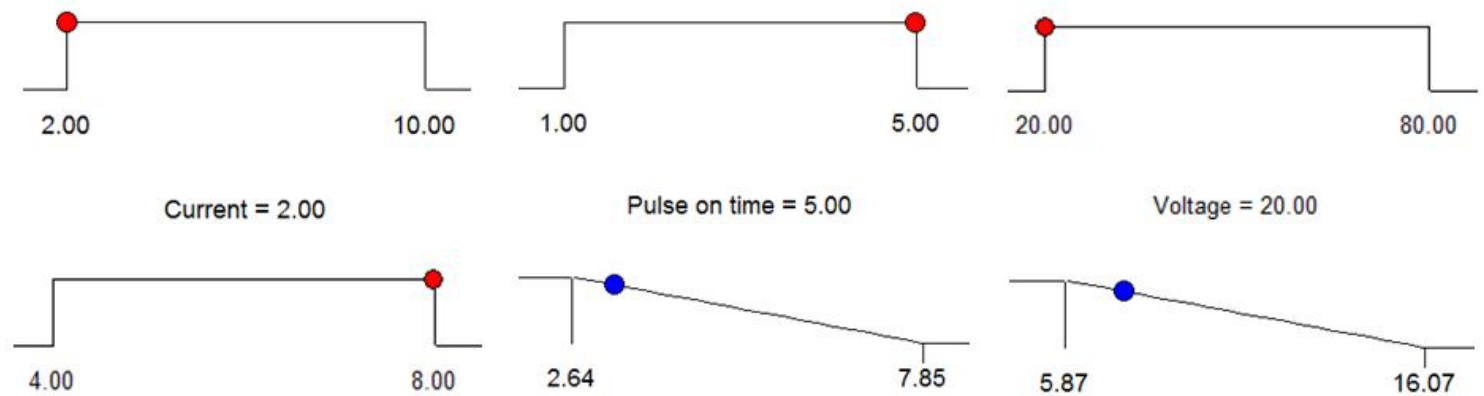

Wire speed $=8.00$
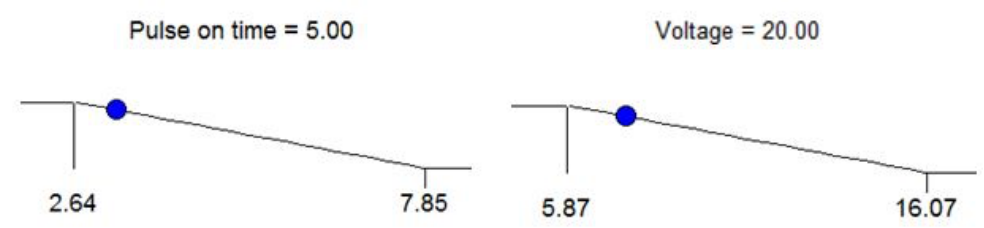

$\mathrm{Rq}=3.28844$

$\mathrm{TW}=7.56796$

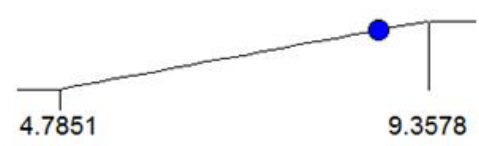

$\operatorname{MRR}=8.7478$

Fig. 12. The ramp graph generated by the DA for the optimal values

The Pareto graphs analyzed can be used to select the optimal values of the process inputs and responses. The explored findings can be considered as a prominent solution in industrial machining. The proposed technique is useful for the optimization of various machining operations. The obtained outcomes can be applied in the expert system and further investigations of the WEDM process.

\section{CONCLUSIONS}

An efficient optimization of the WEDM process of a stainless steel has been considered to decrease the TW as well as the $\mathrm{R}_{q}$ and to improve the MRR. The nonlinear correlations of the machining targets were developed using RBF models. The optimal process inputs and WEDM technical performances were obtained using the MOPSO. The explored findings are summarized:

- The rough surface was observed due to the high values of the inputs. The $\mathrm{R}_{q}$ of SS304 is most influenced by the C, followed by the VO, POT, and SP, respectively. The average value for $\mathrm{R}_{q}$ of $\mathrm{SS} 304$ has a variation of $2.64-7.85 \mu \mathrm{m}$.

- The white layer is formed on the machined WEDM surface due to high energy intensity. The voltage and the current are found to be the most influencing factors on the TW. The wire speed has been found to be a less significant factor. The average value for the TW of SS304 was in a range of 5.87 to $16.07 \mu \mathrm{m}$.

- The high MRR is observed due to the high values of the inputs. The MRR of SS304 is most influenced by the VO, followed by the C, SP, and POT, respectively. The average value for the MRR of SS304 ranges from 4.78508 to $9.35775 \mathrm{~mm}^{3} / \mathrm{min}$. 
- The obtained improvements in the $\mathrm{R}_{q}, \mathrm{TW}$, and MRR are $33.33 \%, 23.53 \%$, and $47.42 \%$ at the optimum selection, as compared to the common values used. The RBFMOPSO performs a higher efficiency than the RSM-DA with the experimental data of the WEDM operation.

\section{ACKNOWLEDGMENT}

This research is funded by Vietnam National Foundation for Science and Technology Development (NAFOSTED) under grant number 107.04-2020.02.

\section{REFERENCES}

[1] A. B. Puri and B. Bhattacharyya. Modeling and analysis of white layer depth in a wire-cut EDM process through response surface methodology. The International Journal of Advanced Manufacturing Technology, 25, (3-4), (2005), pp. 301-307. https://doi.org/10.1007/s00170-0032045-8.

[2] H. Kumar, A. Manna, and R. Kumar. Modeling and desirability approach-based multiresponse optimization of WEDM parameters in machining of aluminum metal matrix composite. Journal of the Brazilian Society of Mechanical Sciences and Engineering, 40, (9), (2018). https://doi.org/10.1007/s40430-018-1368-1.

[3] H. Shahali, M. R. S. Yazdi, A. Mohammadi, and E. Iimanian. Optimization of surface roughness and thickness of white layer in wire electrical discharge machining of DIN 1.4542 stainless steel using micro-genetic algorithm and signal to noise ratio techniques. Proceedings of the Institution of Mechanical Engineers, Part B: Journal of Engineering Manufacture, 226, (5), (2012), pp. 803-812. https://doi.org/10.1177/0954405411434234.

[4] M. Shabgard, S. N. B. Oliaei, M. Seyedzavvar, and A. Najadebrahimi. Experimental investigation and 3D finite element prediction of the white layer thickness, heat affected zone, and surface roughness in EDM process. Journal of mechanical science and technology, 25, (12), (2011), pp. 3173-3183. https://doi.org/10.1007/s12206-011-0905-y.

[5] Y. Shen, Y. Liu, H. Dong, K. Zhang, L. Lv, X. Zhang, X. Wu, C. Zheng, and R. Ji. Surface integrity of Inconel 718 in high-speed electrical discharge machining milling using air dielectric. The International Journal of Advanced Manufacturing Technology, 90, (1-4), (2017), pp. 691698. https://doi.org/10.1007/s00170-016-9332-7.

[6] G. Selvakumar, K. B. Jiju, and R. Veerajothi. Experimental study on wire electrical discharge machining of tapered parts. Arabian Journal for Science and Engineering, 41, (11), (2016), pp. 4431-4439. https://doi.org/10.1007/s13369-016-2145-z.

[7] A. Kumar, V. Kumar, and J. Kumar. Surface crack density and recast layer thickness analysis in WEDM process through response surface methodology. Machining Science and Technology, 20, (2), (2016), pp. 201-230. https://doi.org/10.1080/10910344.2016.1165835.

[8] M. P. Garg, A. Jain, and G. Bhushan. Multi-objective optimization of process parameters in wire electric discharge machining of Ti-6-2-4-2 alloy. Arabian Journal for Science and Engineering, 39, (2), (2014), pp. 1465-1476. https://doi.org/10.1007/s13369-013-0715-x.

[9] A. S. Shivade and V. D. Shinde. Multi-objective optimization in WEDM of D3 tool steel using integrated approach of Taguchi method \& Grey relational analysis. Journal of Industrial Engineering International, 10, (4), (2014), pp. 149-162. https://doi.org/10.1007/s40092-014-0081-7.

[10] D. V. S. S. S. V. Prasad and A. G. Krishna. Empirical modeling and optimization of kerf and wire wear ratio in wire electrical discharge machining. The International Journal of Advanced 
Manufacturing Technology, 77, (1-4), (2015), pp. 427-441. https://doi.org/10.1007/s00170-0146445-8.

[11] H. Majumder and K. P. Maity. Predictive analysis on responses in WEDM of titanium grade 6 using general regression neural network (GRNN) and multiple regression analysis (MRA). Silicon, 10, (4), (2018), pp. 1763-1776. https://doi.org/10.1007/s12633-017-9667-1.

[12] K. Chopra, A. Payla, and E. K. Mussada. Detailed experimental investigations on machinability of EN31 steel by WEDM. Transactions of the Indian Institute of Metals, 72, (4), (2019), pp. 919-927. https://doi.org/10.1007/s12666-018-1552-0.

[13] V. Kumar, V. Kumar, and K. K. Jangra. An experimental analysis and optimization of machining rate and surface characteristics in WEDM of Monel-400 using RSM and desirability approach. Journal of Industrial Engineering International, 11, (3), (2015), pp. 297-307. https://doi.org/10.1007/s40092-015-0103-0.

[14] T. B. Rao and A. G. Krishna. Simultaneous optimization of multiple performance characteristics in WEDM for machining ZC63/SiC $p$ MMC. Advances in Manufacturing, 1, (3), (2013), pp. 265-275. https://doi.org/10.1007/s40436-013-0029-y.

[15] A. Kumar, T. Soota, and J. Kumar. Optimisation of wire-cut EDM process parameter by Greybased response surface methodology. Journal of Industrial Engineering International, 14, (4), (2018), pp. 821-829. https://doi.org/10.1007/s40092-018-0264-8.

[16] B. Keshtegar, C. Mert, and O. Kisi. Comparison of four heuristic regression techniques in solar radiation modeling: Kriging method vs RSM, MARS and M5 model tree. Renewable and sustainable energy reviews, 81, (2018), pp. 330-341. https://doi.org/10.1016/j.rser.2017.07.054.

[17] A. Azadeh, M. H. Farahani, S. S. Kalantari, and M. Zarrin. Solving a multi-objective open shop problem for multi-processors under preventive maintenance. The International Journal of Advanced Manufacturing Technology, 78, (5-8), (2015), pp. 707-722. https://doi.org/10.1007/s00170-014-6660-3.

[18] T. T. Nguyen and X. B. Le. Optimization of roller burnishing process using Kriging model to improve surface properties. Proceedings of the Institution of Mechanical Engineers, Part B: Journal of Engineering Manufacture, 233, (12), (2019), pp. 2264-2282. https://doi.org/10.1177/0954405419835295.

[19] N. L. Thien, N. T. The, and T. N. Quyet. Manufacturing and evaluation of elastic properties of glass fiber reinforced polymers material. Vietnam Journal of Mechanics, 41, (3), (2019), pp. 243255. https://doi.org/10.15625/0866-7136/13721.

[20] M. Watson, H. Long, and B. Lu. Investigation of wrinkling failure mechanics in metal spinning by Box-Behnken design of experiments using finite element method. The International Journal of Advanced Manufacturing Technology, 78, (5-8), (2015), pp. 981-995. https://doi.org/10.1007/s00170-014-6694-6.

[21] G. Fu, H. Gong, H. Gao, T. Gu, and Z. Cao. Integrated thermal error modeling of machine tool spindle using a chicken swarm optimization algorithm-based radial basic function neural network. The International Journal of Advanced Manufacturing Technology, 105, (5-6), (2019), pp. 2039-2055. https://doi.org/10.1007/s00170-019-04388-5.

[22] G. Z. Quan, Z. H. Zhang, X. Wang, A. Mao, and Y. Xia. Parameter optimization of cooling system in U-shape hot stamping mold for high strength steel sheet based on MOPSO. The International Journal of Advanced Manufacturing Technology, 90, (1-4), (2017), pp. 887-906. https://doi.org/10.1007/s00170-016-9446-y.

[23] T. T. Huan and H. P. H. Anh. Comparative stable walking gait optimization for small-sized biped robot using meta-heuristic optimization algorithms. Vietnam Journal of Mechanics, 40, (4), (2018), pp. 407-424. https://doi.org/10.15625/0866-7136/12294. 